\title{
Anatomical and histological study of thyroid gland in female local donkeys (Eqws africanus asinus) at Basrah city
}

\author{
S. A.Ali \\ Coll. of Vet. Med.-Univ. of Basrah
}

\begin{abstract}
Thyroid gland is an endocrine gland that influences many organs of the body and play an important role in the metabolism of animals and another species. Thyroid gland of female donkeys was situated in the interior part of neck inferior to the larynx. It consist of two lobes were connected by isthmus. The mean and SD of length, width, and thickness in right lobe was $25.66 \pm 0.41 \mathrm{~mm}, 21.31 \pm 0.59 \mathrm{~mm}, 8.51 \pm 0.009 \mathrm{~mm}$, while in the left lobe it was $23.15 \pm 0.16$ mm. $19.65 \pm 0.22 \mathrm{~mm}, 8.42 \pm 0.19 \mathrm{~mm}$ respectively. Histologically, the thyroid gland surrounded by connective tissue capsule and contained follicles, follicular epithelium, and parafollicular cells. The follicles filled with colloid.

Key words: Local donkeys, thyroid gland.

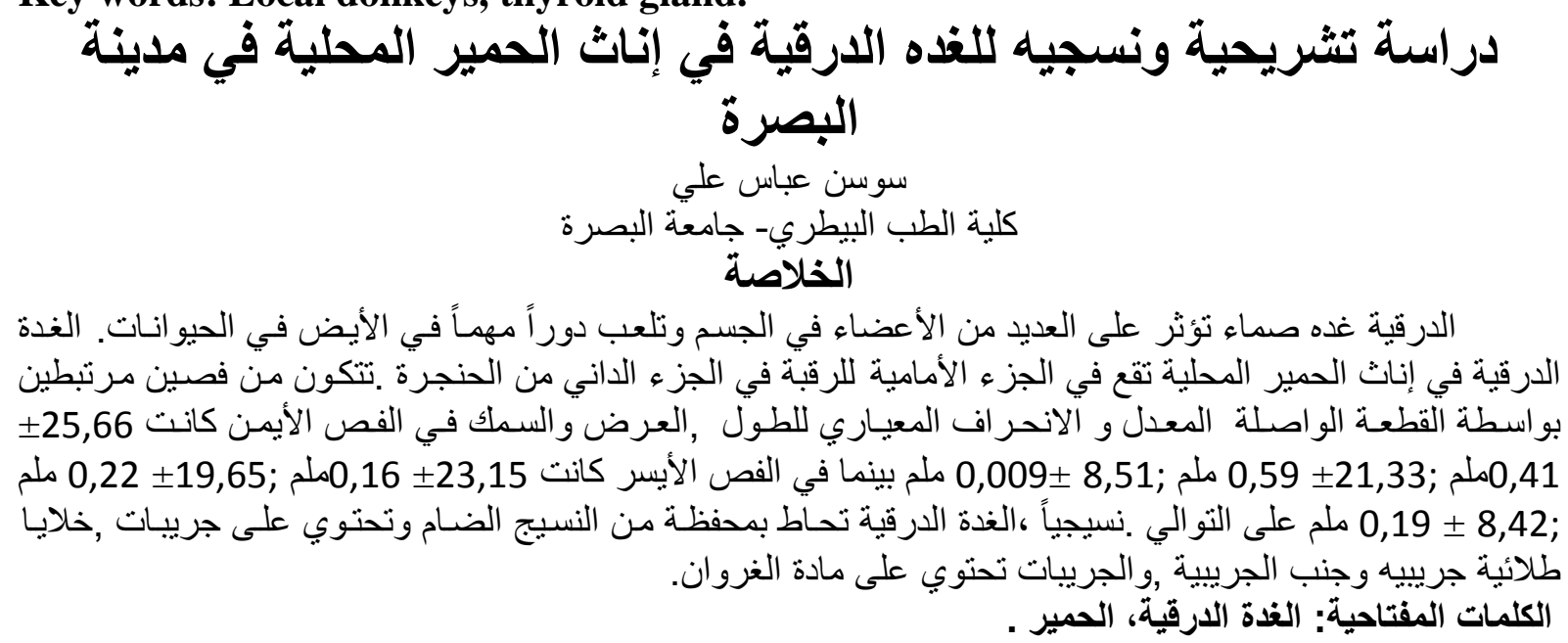

\section{Introduction}

Thyroid gland is considered as the largest endocrine organ(1). (2) observed during their study of thyroid gland in the horse the gland located in anterior part of neck to larynx (lateral sides of lower part larynx), consist of two lobes connected in middle by an isthmus, its cells are arranged into spherical structures called follicles ,which surrounded by reticular fibers and vascular network of capillaries. The gland surrounded by a double connective tissue capsule(3). (4)reported that the thyroid gland in equine are divided into lobes by thin capsule of connective tissue and divided into lobules by thin trabeculae. The lobe consist of follicles of various sizes which filled with colloid ,the follicular cells changes from squamous cell or cuboidal cell in resting stage to cuboidal or columnar in the active stage(5).(6)observed that the anther type of functional cell in thyroid gland called the parafollicular cell which may be found as single cell in the epithelial lining of follicles. The main secretory products of the thyroid gland are thyroxin and triiodothyronine. (Thyrostimulating Hormone) stimulates the endocytosis of from the follicular lumen and the subsequent release of its components into the blood streams, TSH also stimulates their synthesis and release into follicular lumen(7). Because a very little studies in anatomy and histology of thyroid gland in donkey of Basrah city as specific this work was done.

\section{Materials and methods}

Ten adult local donkeys were used in present study after anesthesia, opened in anterior part of neck and removed the thyroid gland. The Thyroid glands are washed with 
distill water and dissected. The length, width and thickness of thyroid gland measured by vernier instrument. The specimen was fixated in $10 \%$ formalin for 3 days, washed by tap water to remove the fixative, dehydration by different alcoholic concentration (ethanol) $70 \%, 80 \%, 90 \%, 100 \%$,clering by the xylene then paraffin Infiltrated and embedded in paraffin block. The section were cut a 5-6um thick by a rotary microtome and staining by Hematoxylin and Eosin $(8,9)$ the examined and pictured by an Elica microscope at $10 \mathrm{X}$ and 40x.

\section{Results}

The anatomical study show, the thyroid gland in female donkeys are oval shape, rough, located in the anterior part of neck inferior to the larynx and associated with the proximal part of trachea (ventrally). The gland consist of two lobes connected by isthmus (fig.1,2). The mean and S.D of length, width and thickness in right part was recorded 25.66,0.41 mm; 21.31,0.59mm; $8.51,0.009 \mathrm{~mm}$ while in left part was23.15,0.16mm; $\quad 19.65,0.22 \mathrm{~mm}$; $8.42,0.19 \mathrm{~mm}$ respectively. The histological results shows; the thyroid gland surrounded by capsule, which consist of connective tissue and the gland divided into two parts or two lobes, right part and left part( fig.3). Each part shows constituted with connective tissue capsule and spherical structures called follicles different in size ,large and small follicles (fig.4). The follicles characterized by the presence of large number of cells called follicular cell are cuboidal epithelial cells and connected by light junctions and have a dense capillary network. the follicles filled with colloid (fig.5,6).The anther functional cells in thyroid gland called parafollicular cells are found in clusters which presence surrounded the follicles and characterized by light cytoplasm (fig .5).

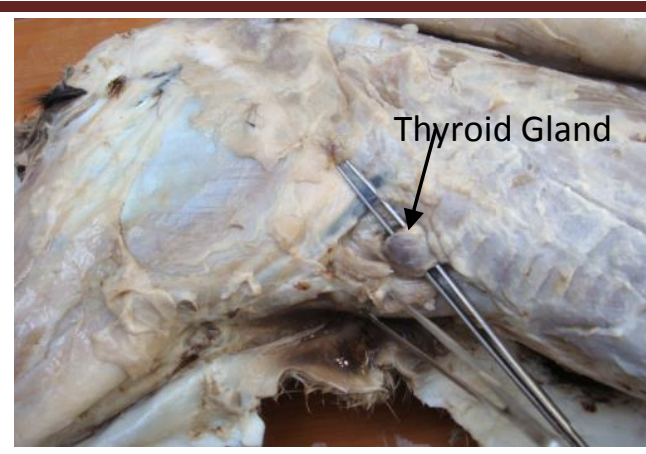

(Fig.1) Thyroid gland of Eqws africanus asinus

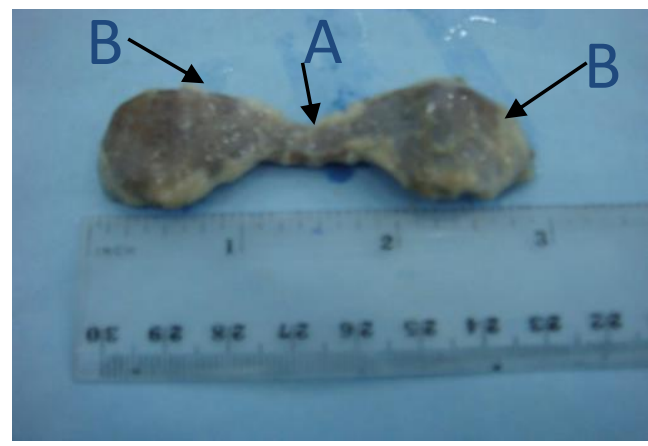

(Fig.2) Thyroid gland show A- Isthmus, B Thyroid lobe

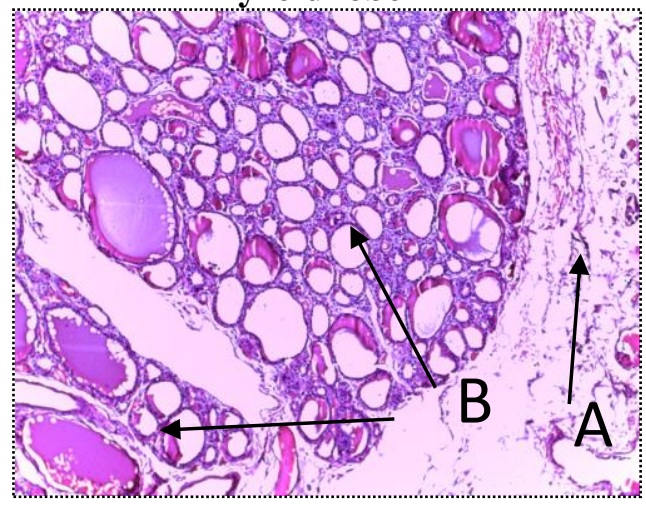

(Fig.3) Section of thyroid show A-Capsule, B Thyroid lobes . H \& E (10 X) .

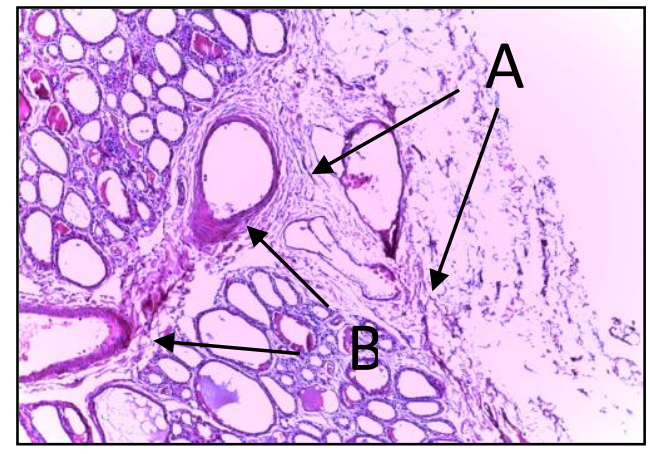

(Fig.4) Section of thyroid gland show $\mathrm{A}$ Connective tissue septa, B-Blood capillaries. H\&E(10X) 


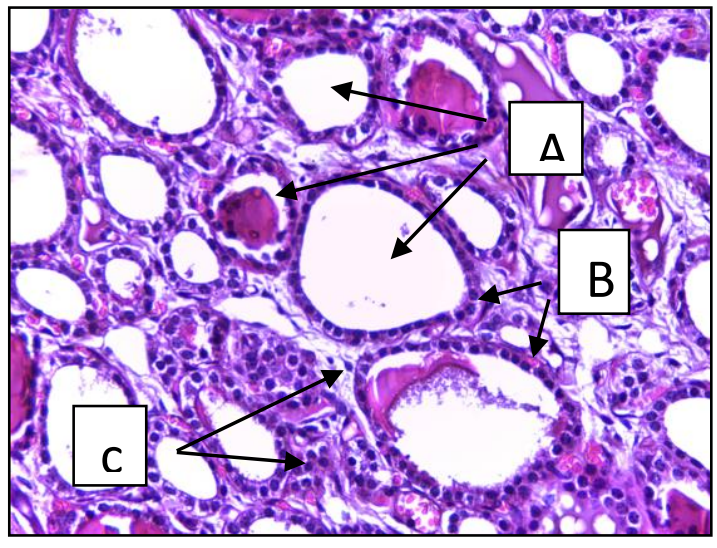

(Fig.5) Section of thyroid gland show, A- follicles, B- follicular cells, C- parafollicular cells. H\&E(10X)

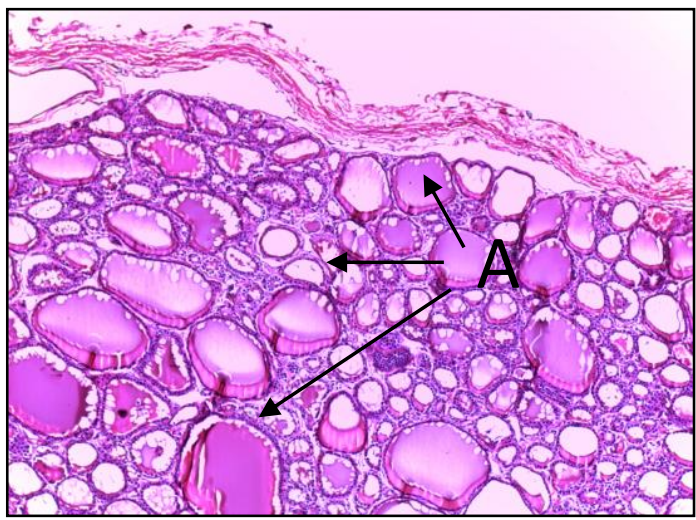

(Fig.6) Section of thyroid gland show A - Colloid H \& E (10 X) .

\section{Discussion}

The study referred that the thyroid gland situated in the anterior neck interior to larynx connected by isthmus, this result agree with $(2,10)$ studies on the horse. The mean of length, width and thickness of lobe in this study differ with (11) during study on the thyroid gland in horse when the length 5-6 $\mathrm{cm}$, and also disagreement with (12) which study on the female camels found the length, width and thickness of thyroid gland recorded 5.55,0.5;2.65,0.3, and 0.9,0.25 cm respectively .The histological result of thyroid gland in female donkey showed that the gland surrounded by connective tissue capsule and divided into two lobes or parts, this result agree with (4) who studies the thyroid gland in equine. Each lobe is surrounded by connective tissue capsule and divided into lobules by thin trabecular. That agreed with anther studies $(4,5)$ during study on demotic animals. The lobules shows consist of follicles which various size and filled with colloid, this study similar with (12) during the thyroid gland in the humped camel. The anther functional cells called parafolliculer cells which few number and present between the follicular structures and light cytoplasm. This study agrees with $(6$, 7).

blue histology enocrines, school of Anatomy and human biology ,The university of Western Austeralia pp:

8-Galigher, A.E. and Kozolff,E.N. (1964). Essential particle MICROTECHNIQUE, Leu and fubrigar philadephia p'p:42-44.Luna,L.G.(1968) Manual of Histological , $3{ }^{\text {rd }}$ edition , Grow-Hill book:11-28.

9-Coortesy,A. and Gefferies (2008) Thyroid gland,Anatomy and Physiology learning resources: $1-5$.

10-Sisson ,S.(1968)Anatomy of demostic Animal ,thyroid gland ,W.B Sounders company phildiaphia and london:546-547.

11-Ahmadpanahi,S . M. and Yousefli ,M .R.(2012).Anatomical and histological study on thyroid gland in on humped camel (camelus dromedarious):273-287. 